\title{
Glycerol chlorination in a gas-liquid semibatch reactor: New catalysts for chlorohydrin production
}

\author{
R. Vitiello, V. Russo, R. Turco, R. Tesser*, M. Di Serio, E. Santacesaria \\ Department of Chemicals Sciences, University of Study of Naples "Federico II", 80126 Naples, Italy
}

\section{A R T I C L E I N F O}

Article history:

Received 24 February 2014

Accepted 7 March 2014

Published 20 May 2014

\section{Keywords:}

Glycerol chlorination

Chlorohydrins

Epichlorohydrin

Hydrochloric acid gas

\begin{abstract}
A B S T R A C T
Glycerol from biodiesel production can be an important industrial feedstock for chemical commodities as it can be used in the food, cosmetic, pharmaceutical and tobacco industries. However, crude glycerol derived from biodiesel production has a low value because of impurities. The purification of this glycerol into a high grade involves high costs and is not economically feasible for small and medium size plants. The glycerol conversion into chlorohydrins was studied using new homogeneous catalysts and hydrochloric acid as chlorination agent. This is an interesting alternative route to epichlorohydrin and then to epoxy resins. The behavior of two series of homologous catalysts, glycolic acid series (glycolic acid, di-glycolic acid and thio-glycolic acid) and amminoacid series (glutamic acid, aspartic acid and cysteine), were investigated for their activity and selectivity. Glycolic acids were more active than amminoacids. The $\mathrm{p} K_{\mathrm{a}}$ values had a strong influence on selectivity (mono-chlorohydrins/di-chlorohydrins) for the amminoacid series, which was not observed for the glycolic acids. A kinetic model and reaction mechanism developed in a previous work were used for interpreting the kinetic runs.
\end{abstract}

(C) 2014, Dalian Institute of Chemical Physics, Chinese Academy of Sciences. Published by Elsevier B.V. All rights reserved.

\section{Introduction}

In the past few years, biodiesel production has greatly increased, leading to the availability of crude glycerol, which is the main byproduct in the synthesis of this biofuel [1]. However, the resulting glycerol contains many impurities and its high grade refining involves considerable additional costs. It would be useful, therefore, to find new applications for this byproduct that does not demand too much purification.

Glycerol is a material of utility in many application areas and there are several methods available to convert glycerol into value-added products. For example, glycerol can be converted thermochemically to propylene glycol [1,2], acetol [3] and a wide variety of products $[4,5]$. A reforming process in aqueous phase which transforms glycerol into hydrogen [6] has also been proposed. Furthermore, glycerol can be used as a feed- stock in many fermentation processes in the biotechnological industry $[7,8]$.

Another interesting alternative use of glycerol consists of the halogenation reaction, in particular chlorination for the production of dichlorohydrins, which are the intermediates for epichlorohydrin synthesis. Epichlorohydrin production by the glycerol-based route is one of several new opportunities that have been proposed for the use of readily available low cost glycerol. Epichlorohydrin is an important basic raw material for the synthesis of different products such as epoxide resins, synthetic elastomers and sizing agents for the papermaking industry.

The traditional process for epichlorohydrin production consists of two steps: allyl chloride is obtained at a relatively high temperature in a first chlorination step [9] and a mixture of dichlorohydrin isomers is produced from the reaction between

\footnotetext{
* Corresponding author. Tel: +39-081-674012; E-mail: riccardo.tesser@unina.it 
allyl chloride and hypochlorous acid, and a further reaction step to the target product, epichlorohydrin, by the reaction of the dichlorohydrin mixture with sodium or calcium hydroxide. The composition of the dichlorohydrin isomer mixture is approximately $70 \%$ 1,2-dichloropropanol $(\alpha, \beta-\mathrm{DCH})$ and $30 \%$ 1,3-dichloropropanol $(\alpha, \gamma-\mathrm{DCH})$. This can be problematic because the subsequent reaction to epichlorohydrin is much slower when $\alpha, \beta-\mathrm{DCH}$ is involved. This gives serious problems for the unit operations because they must be sized on the basis of the lowest reaction rate. So the selective production of $\alpha, \gamma$-DCH is interesting.

From these considerations, an alternative process for the direct chlorination of glycerol with hydrogen chloride leading to the formation of the single desired isomer is very promising. As a matter of fact, this route is rather old but the original process involved the reaction of glycerol with aqueous hydrochloric acid and acetic acid as catalyst at a temperature in the range 80-100 ${ }^{\circ} \mathrm{C}[10]$.

The present paper presents an extensive investigation on the catalytic and kinetic aspects of this reaction. The conversion of glycerol into useful chlorinated products by its reaction with gaseous hydrogen chloride catalyzed by new catalysts was investigated. The products were 1,3-chloro-2-propanol $(\alpha, \gamma$-DCH), 1,2-chloro-3-propanol $(\alpha, \beta$-DCH), 1-chloro-2,3-propanediol $(\alpha-\mathrm{MCH})$ and 2-chloro-1,3-propanediol $(\beta-\mathrm{MCH})$.

The reaction proceeds through a first chlorination step of glycerol that primarily formed $\alpha-\mathrm{MCH}$ and water with small quantities of $\beta-\mathrm{MCH}$. This was followed by a second chlorination reaction where $\alpha, \gamma$-DCH was obtained with modest amounts of $\alpha, \beta$-DCH as a byproduct. The reaction network is shown in Scheme $1[11,12]$. Since the catalyst is an organic acid, its direct chlorination is also possible, but this was excluded because the corresponding acylic chlorides was produced by using $\mathrm{SOCl}_{2}$ as chlorinating agent, and in the presence of hydrogen chloride, the chlorination of the acid cannot occur [13].

As mentioned above, the reaction between glycerol and hydrogen chloride was traditionally catalyzed by acetic acid (AA) $[11,12]$. However, this catalyst is too volatile under typical reaction conditions and should be replaced by a less volatile catalyst to allow operation at a higher temperature. Another important aspect of the proposed chlorohydrins synthesis route is that in an industrial plant, the catalyst and reaction products would be separated by fractional distillation. This separation would not be a difficult task due to the broad range of boiling points [14].

Santacesaria et al. $[11,12,15]$ performed a comparison of the

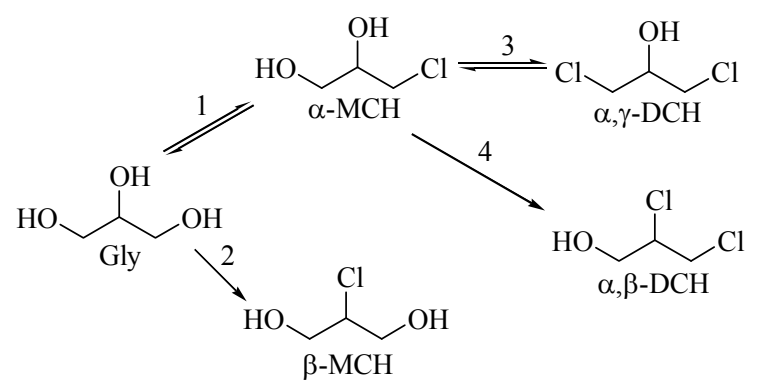

Scheme 1. Reaction network for glycerol chlorination. kinetic behavior of different catalysts (mainly carboxylic acids) and proposed a correlation between the $\mathrm{p} K_{\mathrm{a}}$ of the different acids and the activity and selectivity. Luo et al. [16] and Lim et al. [17] have developed a kinetic model for glycerol chlorination in the presence of acetic acid as catalyst that can be considered the reference catalyst for this reaction [12,18-21]. The proposed kinetic model is based on a simplifying monophasic approximation that does not consider the formation of the intermediates in the chlorination reaction, such as esters formed from glycerol and the catalytic species. A more sophisticated model is necessary for a proper description of the chemical and physical phenomena occurring in the chlorination reaction. Moreover, the $\mathrm{p} K_{\mathrm{a}}$ value of the catalyst is not sufficient as a single criterion to describe the kinetic behavior of different carboxylic acids as catalyst, and a further correlation between the molecular structure and catalytic activity would be useful to characterize the best catalyst. The main purpose of this work was to continue the testing of new catalysts for this reaction with the aim to find the most active and selective catalysts with a performance comparable to acetic acid but which are less volatile and more stable.

\section{Experimental}

This work employed (in the glycerol chlorination reaction) two sets of homologous catalysts: a series of aminoacids and a series of glycolic acids. The main scope of the work was to compare their activity for chlorination and to acquire scientific insight about the effect of the different functional groups in the catalyst molecule on its activity and product distribution, that is, selectivity to monochlorohydrins (MCHs) and dichlorohydrins (DCHs).

All experiments were carried out in a $300 \mathrm{~cm}^{3}$ Hastelloy steel reactor equipped with a magnetically driven stirrer and temperature and pressure measuring devices. In the experimental setup, both a system for sample withdrawal and a series of Drechsel bottles for neutralizing excess hydrogen chloride were installed. The reactor has been described in our previous work [11]. Glycerol and catalyst were first loaded into the reactor, then the reactor was sealed and air removed with a vacuum pump and the reaction mixture was heated to the desired temperature. When the desired temperature was reached, $\mathrm{HCl}$ was fed into the reactor from an external cylinder using a $\mathrm{HCl}$ inlet volumetric flow rate that compensated for hydrochloric acid consumption by the reaction to keep the pressure constant. The tests were performed under the same conditions of temperature, pressure and stirring speed, using $T=100{ }^{\circ} \mathrm{C}, p=$ 4.5 bar, catalyst concentration $=8 \mathrm{~mol} \%$ with respect to glycer$\mathrm{ol}$, reaction time $=4 \mathrm{~h}$, and stirring rate $=1000 \mathrm{r} / \mathrm{min}$.

For each run, liquid phase samples were withdrawn at 1, 3 and $4 \mathrm{~h}$ to get the concentration versus time profiles. These samples after neutralization with excess sodium bicarbonate were analyzed on a gas chromatograph to get the glycerol conversion and chlorinated product distribution. At the end of the run, after $4 \mathrm{~h}$ of reaction, the $\mathrm{HCl}$ in excess was discharged from the system by bubbling into a trap containing $\mathrm{NaOH}$. Stirring was then stopped and the system was cooled to room temper- 
ature.

The GC column used for the analysis was a CHROMPACK CPWax, with a stationary phase of $100 \%$ polyethylene-glycol, length of $30 \mathrm{~m}$, I.D. of $0.25 \mathrm{~mm}$ and film thickness of $0.25 \mu \mathrm{m}$. The GC was equipped with a FID detector and used helium as the carrier gas. The other parameters were: injector temperature $=250{ }^{\circ} \mathrm{C}$, detector temperature $=280{ }^{\circ} \mathrm{C}$, temperature program $=1 \mathrm{~min}$ at $40{ }^{\circ} \mathrm{C}$, heating rate $20{ }^{\circ} \mathrm{C} / \mathrm{min}$ to $100{ }^{\circ} \mathrm{C}$ then $40{ }^{\circ} \mathrm{C} / \mathrm{min}$ up to $200^{\circ} \mathrm{C}$, finally hold for $10 \mathrm{~min}$. The withdrawn sample was first diluted with methanol in a volumetric ratio of $1: 30$ and $1 \mu \mathrm{L}$ of the resulting solution was injected into the GC. The quantitative analysis was expressed as mole percent normalized with respect to the sum of known components.

The catalysts in the series of glycolic acids were glycolic acid (GA), thioglycolic acid (TGA) and diglycolic acid (DGA). In the amino acids series, the following catalysts were tested: cysteine (CYS), aspartic acid (ASPA) and glutamic acid (GLUA). All reagents were purchased from Sigma Aldrich at the highest purity available (glycerol anhydrous $>99.0 \%$ and catalyst $>99.0 \%$ ) and used as received without further purification. Gaseous hydrochloric acid was purchased from Air Liquide Italy (99.8 vol\%).

\section{Results and discussion}

An overview of the experiments is reported together with the experimental conditions and amounts of reactants loaded in the reactor in Table 1.

A first comparison of the catalysts can be made in terms of the product distribution after $4 \mathrm{~h}$ of reaction time, which is reported in Table 2 for the experimental runs performed at a constant pressure of 4.5 bar and temperature of $100{ }^{\circ} \mathrm{C}$.

The data in Table 2 for the first set of catalysts (amino acids)

Table 1

Reactor experimental conditions.

\begin{tabular}{lcccccc}
\hline Run & Catalyst & $m($ cat $) / \mathrm{g}$ & $m(\mathrm{Gly}) / \mathrm{g}$ & $T /{ }^{\circ} \mathrm{C}$ & $p / \mathrm{bar}$ & $\mathrm{p} K_{\mathrm{a}}$ \\
\hline 1 & ASPA & 17.30 & 150 & 100 & 4.5 & 3.90 \\
2 & GLUA & 19.13 & 150 & 100 & 4.5 & 4.07 \\
3 & CYS & 15.75 & 150 & 100 & 4.5 & 8.37 \\
4 & GA & 9.89 & 150 & 100 & 4.5 & 3.83 \\
5 & DGA & 17.43 & 150 & 100 & 4.5 & 2.90 \\
6 & TGA & 11.98 & 150 & 100 & 4.5 & 3.73 \\
7 & GLUA & 4.80 & 150 & 100 & 4.5 & 4.07 \\
8 & GLUA & 9.60 & 150 & 100 & 4.5 & 4.07 \\
9 & GLUA & 19.13 & 150 & 100 & 1.0 & 4.07 \\
10 & GLUA & 19.13 & 150 & 100 & 8.0 & 4.07 \\
$11[10]$ & AA & 7.8 & 150 & 100 & 8.0 & 4.79 \\
\hline & & & & & &
\end{tabular}

Table 3

Product distribution after $4 \mathrm{~h}$ reaction with GLUA as catalyst.

\begin{tabular}{|c|c|c|c|c|c|c|c|}
\hline \multirow{2}{*}{ Run * } & \multicolumn{5}{|c|}{ Product (mol\%) } & \multicolumn{2}{|c|}{ Selectivity (mol\%) } \\
\hline & $\alpha-\mathrm{MCH}$ & $\beta-\mathrm{MCH}$ & $\alpha, \gamma-\mathrm{DCH}$ & $\alpha, \beta-\mathrm{DCH}$ & Gly & MCHs & DCHs \\
\hline 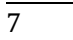 & 64.2 & 6.4 & 287 & 0.7 & 0 & 70 & 29.4 \\
\hline 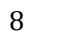 & 5 & 7. & 40.7 & 1.0 & 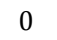 & 58 & 41.7 \\
\hline 2 & 22.2 & 4.3 & 72.3 & 1.2 & 0 & 26.5 & 73.5 \\
\hline 9 & 74.2 & 6.2 & 12.7 & 0.4 & 6.5 & 86.0 & 14.0 \\
\hline 10 & 7.9 & 8.1 & 81.6 & 2.4 & 0 & 16.0 & 84.0 \\
\hline
\end{tabular}

* The reaction conditions are the same as in Table 1.

showed that a total conversion of glycerol was reached only with glutamic acid. This catalyst also showed a relatively high selectivity to $\alpha, \gamma-\mathrm{DCH}$, resulting in a performance similar to acetic acid, but with the advantage of very low volatility (melting point $199{ }^{\circ} \mathrm{C}$ and soluble in the reaction mixture). Also, it was observed that ASPA and GLUA with only two carboxylic groups and a similar $\mathrm{p} K_{\mathrm{a}}$ value showed a higher activity than CYS. ASPA and CYS were more selective to monochlorohydrin production, while dicholorohydrins were the main products when GLUA was used as catalyst.

The results of glycolic acids as catalyst are also reported in Table 2. All the catalysts in this set showed complete conversion of glycerol. In every case, a mixture of mainly $\alpha-\mathrm{MCH}$ and $\alpha, \gamma$-DCH was obtained, while thioglycolic acid produced more dichlorohydrins than monochlorohydrins.

From this first catalyst screening, it was concluded that glutamic acid has the best performance, both in terms of activity and selectivity to the desired product, dichlorohydrins. For this reason, this catalyst was used in further studies to investigate the effect of hydrochloric acid pressure (runs 9 and 10 in Table1) and catalyst amount (runs 7 and 8 in Table 1). The results are reported in Table 3 and Figs. 1 and 2.

The tests reported in Table 3 were carried out at different pressures and different catalyst amounts. Tests 2,7 , and 8 were performed at constant pressure using 2, 4, and $8 \mathrm{~mol} \%$ catalyst, while tests 2,9 , and 10 were at a constant catalyst amount (8 mol\%) at 4.5, 1.0, and 8.0 bar of $\mathrm{HCl}$ pressure.

It can be seen in Fig. 1 that the increase of $\mathrm{HCl}$ pressure has a positive effect on both the activity and selectivity. At 1.0 bar, complete conversion of glycerol was not reached even after $4 \mathrm{~h}$ reaction, while at 4.5 bar, the glycerol was completely converted and the selectivity to dichlorohydrins was high. A further increase of pressure to 8.0 bar resulted in a further increase of selectivity, reaching $84 \mathrm{~mol} \% \alpha, \gamma$-DCH. The observed behavior can be explained by that an increase of pressure led to increased $\mathrm{HCl}$ solubility. The concentration versus time profiles

Table 2

Product distribution after $4 \mathrm{~h}$ reaction, $T=100^{\circ} \mathrm{C}$, catalyst $8 \mathrm{~mol} \%$ - amino acids series and glycolic acids series.

\begin{tabular}{|c|c|c|c|c|c|c|c|c|}
\hline \multirow{2}{*}{ Run } & \multirow{2}{*}{ Catalyst } & \multicolumn{5}{|c|}{ Product (mol\%) } & \multicolumn{2}{|c|}{ Selectivity (mol\%) } \\
\hline & & $\alpha-\mathrm{MCH}$ & $\beta-\mathrm{MCH}$ & $\alpha, \gamma-\mathrm{DCH}$ & $\alpha, \beta-\mathrm{DCH}$ & Gly & MCHs & DCHs \\
\hline 1 & ASPA & 69.1 & 6.6 & 13.4 & 0.4 & 10.5 & 84.6 & 15.4 \\
\hline 2 & GLUA & 22.2 & 4.3 & 72.3 & 1.2 & 0 & 26.5 & 73.5 \\
\hline 3 & CYS & 50.1 & 5.3 & 3.4 & 0.2 & 41.0 & 93.9 & 6.1 \\
\hline 4 & GA & 48.4 & 5.2 & 45.4 & 1.0 & 0 & 53.6 & 46.4 \\
\hline 5 & DGA & 57.4 & 0.7 & 40.8 & 1.1 & 0 & 58.1 & 41.9 \\
\hline 6 & TGA & 32.4 & 5.6 & 60.6 & 1.4 & 0 & 38.0 & 62.0 \\
\hline 11 [10] & AA & 0.6 & 7.5 & 89.3 & 2.6 & 0 & 8.4 & 91.6 \\
\hline
\end{tabular}




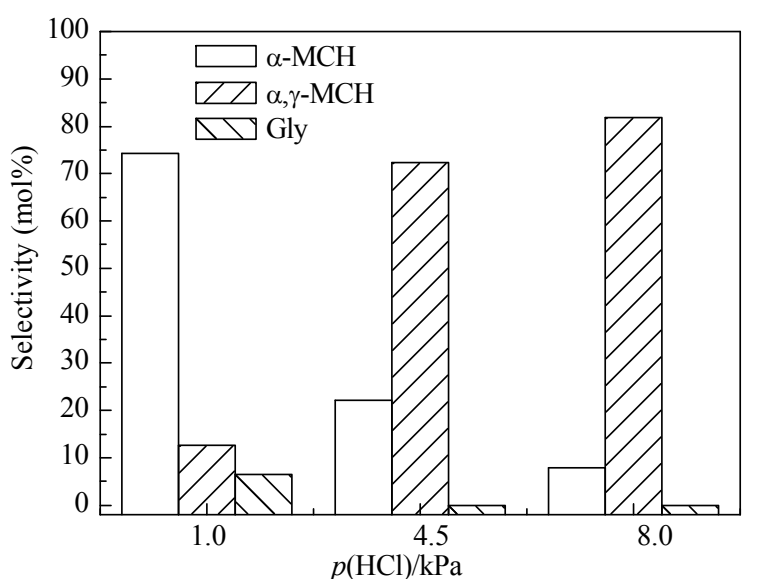

Fig. 1. Product selectivity after $4 \mathrm{~h}$ using GLUA at different $\mathrm{HCl}$ pressures.

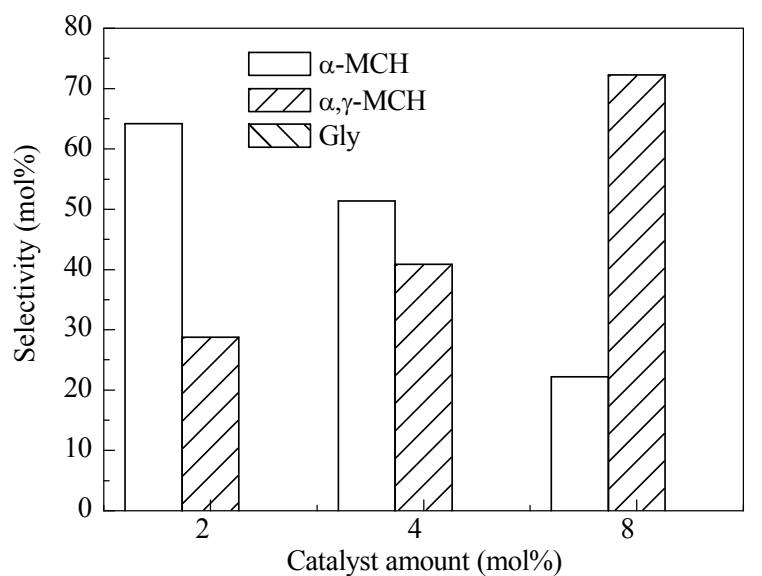

Fig. 2. Product selectivity after $4 \mathrm{~h}$ reaction using GLUA at $p=4.5 \mathrm{bar}, T$ $=100{ }^{\circ} \mathrm{C}$, and different catalyst amounts.

for this set of runs are reported in Fig. 6.

The effect of catalyst amount was studied by using a medium pressure of 4.5 bar and $100^{\circ} \mathrm{C}$, while the GLUA amount was varied as reported in Table 1 (runs 2,7 , and 8). The results are shown in Fig. 2.

In all the tests of this group, unlike the tests carried out at different pressures, there was no glycerol residue, and in every case, monochlorohydrins and dichlorohydrins were the only detected compounds.

From 2 to $8 \mathrm{~mol} \%$ catalyst, the selectivity gradually shifted from monochlorohydrins to dichlorohydrins as can be expected from the reaction sequence. The concentration versus time profiles for this set of runs are reported in Fig. 7.

\section{Kinetics and modelling}

All the experimental data were simulated by a gas-liquid kinetic model that has been reported elsewhere [11]. When all the reactions were assumed reversible, previous investigations have demonstrated that only the formation of $\alpha$-monochlorohydrin and $\alpha, \gamma$-dichlorohydrin showed a small equilibrium constant $[10-12,14]$. In this respect, the kinetic constants of their reverse reactions were quite small (see Table 4) and likely negligible. The constants for $\beta$-monochlorohydrin and $\alpha, \beta$-dichlorohydrin products were lower by some orders of magnitude, and so they were excluded from the present model. In summary, the model assumed that the formations of $\beta$-monochlorohydrin and $\alpha, \beta$-dichlorohydrin were irreversible reactions, while the other chlorination steps were reversible. The following simplified reaction scheme with related reaction rate expressions, all expressed in ( $\mathrm{mol} /(\mathrm{L} \cdot \mathrm{min}))$, was

$$
\begin{gathered}
\mathrm{Gly}+\mathrm{HCl} \leftrightarrow \alpha-\mathrm{MCH}+\mathrm{H}_{2} \mathrm{O} \\
r_{1}=[\mathrm{CAT}] \cdot\left(k_{1} \cdot[\mathrm{Gly}] \cdot[\mathrm{HCl}]-k_{-} \cdot\left[\mathrm{H}_{2} \mathrm{O}\right] \cdot[\alpha-\mathrm{MCH}]\right) \\
\mathrm{Gly}+\mathrm{HCl} \rightarrow \beta-\mathrm{MCH}+\mathrm{H}_{2} \mathrm{O} \\
r_{2}=[\mathrm{CAT}] \cdot\left(k_{2} \cdot[\mathrm{Gly}] \cdot[\mathrm{HCl}]\right) \\
\alpha-\mathrm{MCH}+\mathrm{HCl} \leftrightarrow \alpha, \gamma-\mathrm{DCH}+\mathrm{H}_{2} \mathrm{O} \\
r_{3}=[\mathrm{CAT}] \cdot\left(k_{3} \cdot[\alpha-\mathrm{MCH}] \cdot[\mathrm{HCl}]-k_{-} \cdot\left[\mathrm{H}_{2} \mathrm{O}\right] \cdot[\alpha, \gamma-\mathrm{DCH}]\right) \\
\alpha-\mathrm{MCH}+\mathrm{HCl} \rightarrow \alpha, \beta-\mathrm{DCH}+\mathrm{H}_{2} \mathrm{O} \\
r_{4}=[\mathrm{CAT}] \cdot\left(k_{4} \cdot[\alpha-\mathrm{MCH}] \cdot[\mathrm{HCl}]\right)
\end{gathered}
$$

As a simplifying assumption, the reverse of reaction (3) has the same kinetic constant as reaction (1). With this approach, the model contained less adjustable parameters. Moreover, it has been verified that the use of different reverse rate constants did not improve significantly the fitting of experimental data and the two obtained constants $\left(k_{-1}\right.$ and $\left.k_{-3}\right)$ have practically the same value.

To describe the evolution with time of each chemical compound, the mass balance was written as follows.

$$
\frac{1}{V} \cdot \frac{\mathrm{d} n_{m}^{i}}{\mathrm{~d} t}=\sum r_{k}+\sum J_{m}-F_{m}
$$

where $n_{m}^{i}$ stands for moles of the $m^{\text {th }}$ chemical specie, $i$ for the phase (gas or liquid), $V$ is the reaction volume, $r_{\mathrm{k}}$ the reaction rate expression, $J_{\mathrm{m}}$ the volumetric mass transfer rate and $F_{\mathrm{m}}$ the volume of sample withdrawn from the system. For the gas-liquid $\mathrm{HCl}$ mass transfer, the Whitman two film theory was adopted by using the following mass transfer rate expression.

$$
J_{\mathrm{HCl}}=k_{\mathrm{L}} \cdot \mathrm{a} \cdot\left([\mathrm{HCl}]^{*}-[\mathrm{HCl}]\right)=\beta \cdot\left([\mathrm{HCl}]^{*}-[\mathrm{HCl}]\right)(\text { in } \mathrm{mol} /(\mathrm{L} \cdot \mathrm{min}))
$$

The mass transfer coefficient $\beta$ was considered an additional adjustable parameter, while the solubility was calculated using the UNIFAC model (see [11] for details). By solving the ordinary differential equation system (5), it was possible to obtain by mathematical regression analysis on the experimental data the kinetic constants reported in Table 4, and the fits in Fig. 3 and Fig. 4. The overall agreement between experimental data and the kinetic model is shown in Fig. 5 in the form of a parity plot in which all experimental molar compositions were reported as a function of the calculated ones.

Table 4

Kinetic and mass transfer parameters obtained by mathematical regression analysis.

\begin{tabular}{lcccccc}
\hline \multirow{2}{*}{ Catalyst } & \multicolumn{5}{c}{ Kinetic parametor $\left(\left(\mathrm{cm}^{3} / \mathrm{mol}\right)^{2} / \mathrm{min}\right)$} & \multirow{2}{*}{$B$} \\
\cline { 2 - 5 } & $k_{1}$ & $k_{2}$ & $k_{3}$ & $k_{4}$ & $k_{-1}$ & $\left(\mathrm{~min}^{-1}\right)$ \\
\hline ASPA & $1.56 \mathrm{E}+04$ & $1.14 \mathrm{E}+03$ & $1.69 \mathrm{E}+03$ & $2.59 \mathrm{E}+00$ & $1.44 \mathrm{E}-05$ & 0.0211 \\
GLUA & $3.47 \mathrm{E}+04$ & $1.91 \mathrm{E}+03$ & $6.72 \mathrm{E}+03$ & $8.28 \mathrm{E}-01$ & $6.05 \mathrm{E}-13$ & 0.0534 \\
CYS & $1.61 \mathrm{E}+03$ & $1.62 \mathrm{E}+02$ & $2.65 \mathrm{E}+02$ & $9.81 \mathrm{E}-01$ & $3.19 \mathrm{E}-06$ & 0.0458 \\
GA & $2.71 \mathrm{E}+04$ & $1.78 \mathrm{E}+03$ & $2.28 \mathrm{E}+03$ & $6.56 \mathrm{E}-01$ & $2.61 \mathrm{E}-12$ & 0.0682 \\
DGA & $1.95 \mathrm{E}+04$ & $8.20 \mathrm{E}+02$ & $2.69 \mathrm{E}+03$ & $1.38 \mathrm{E}+00$ & $5.17 \mathrm{E}-06$ & 0.0390 \\
TGA & $0.98 \mathrm{E}+05$ & $6.41 \mathrm{E}+03$ & $5.37 \mathrm{E}+03$ & $9.20 \mathrm{E}-01$ & $1.06 \mathrm{E}-05$ & 0.0501 \\
\hline
\end{tabular}




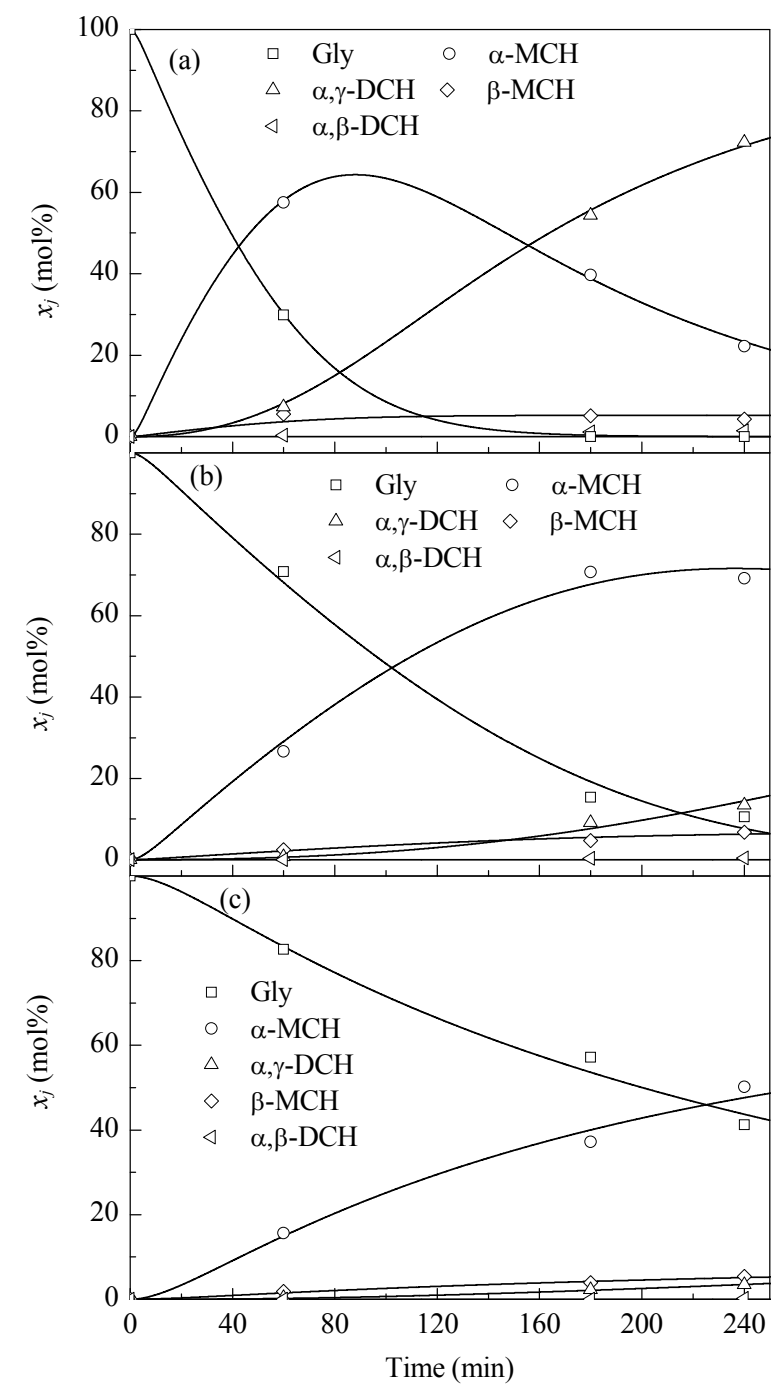

Fig. 3. Product distribution and glycerol consumption for catalysts GLUA (a), ASPA (b), and CYS (c). $p=4.5$ bar, $T=100^{\circ} \mathrm{C}$, catalyst amount $8 \mathrm{~mol} \%$.

It can be appreciated from these diagrams that the fit was satisfactory. The profiles reported in Fig. 6 and Fig. 7 indicated that the model was able to describe quite correctly also the runs at different pressure and catalyst concentration.

For the gas-liquid mass transfer coefficient $\beta$, the values obtained (reported in Table 4) were all of the same order of magnitude with an average value of $5.42 \times 10^{-2} \mathrm{~min}^{-1}$, which was lower than the average value obtained in our previous work (about $3 \mathrm{~min}^{-1}$ ) [11] for different catalysts. This difference in gas-liquid mass transfer behaviour can be explained by that the catalysts investigated in the present work were much more active, so a lower value of $\beta$ can be considered reasonable.

A further interesting consideration was obtained from the kinetic constants obtained by mathematical regression. These constants were related to the activity and selectivity of the catalysts. This effect can be better appreciated from their ratios reported in Table 5 . The ratio $k_{1} / k_{2}$ indicated that all the catalysts were very selective for the production of $\alpha-\mathrm{MCH}$ with respect to $\beta-\mathrm{MCH}$ in the first chlorination step. This is a significant advantage because a high concentration of $\beta$-MCH gives a

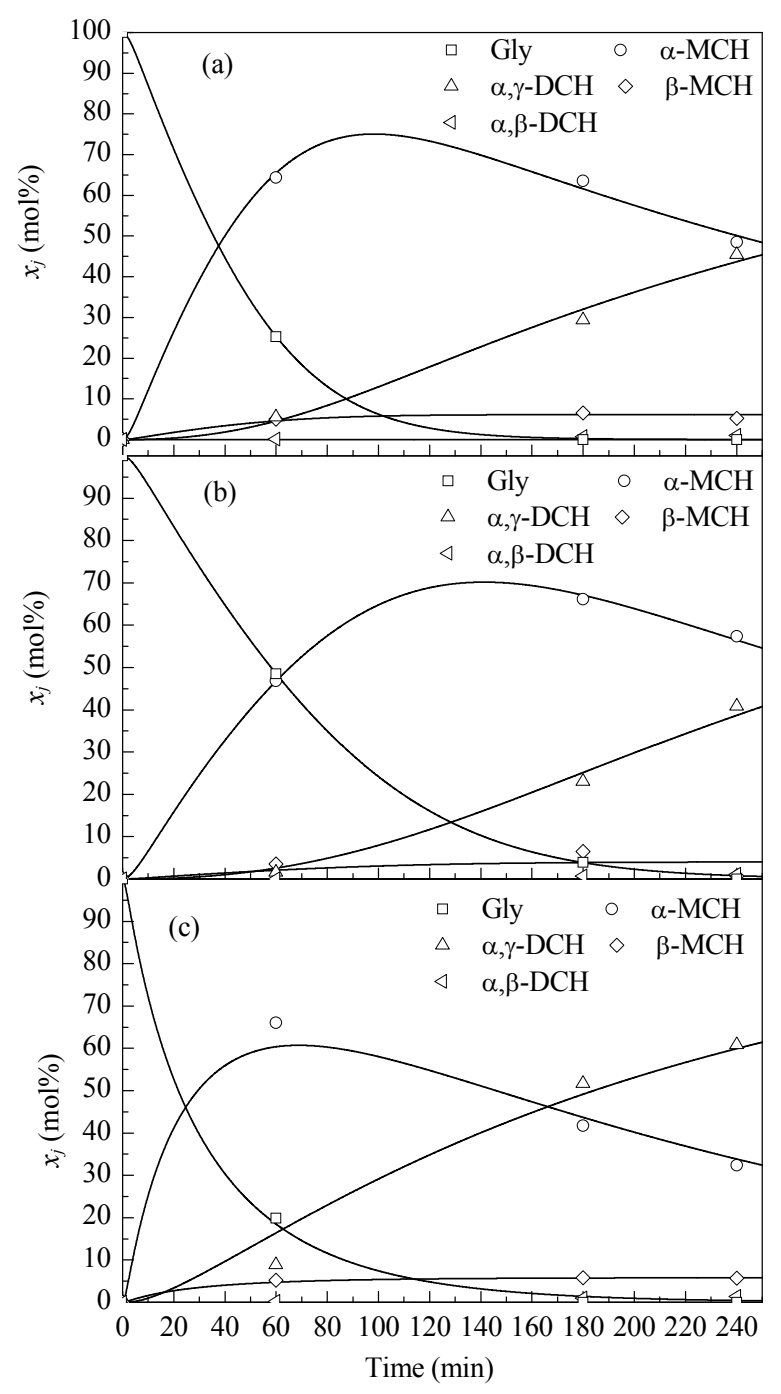

Fig. 4. Product distribution and glycerol consumption for catalysts GA (a), DGA (b), and TGA (c). $p=4.5$ bar, $T=100{ }^{\circ} \mathrm{C}$, catalyst amount 8 mol\%.

serious separation problem from $\alpha$-MCH in industrial plants. In our case, we have always observed $\beta$-MCH molar concentrations lower than those obtained with acetic acid (see Table2). A very similar, even more pronounced behavior, can be appreciated from the ratio $k_{3} / k_{4}$ for the high selectivity toward

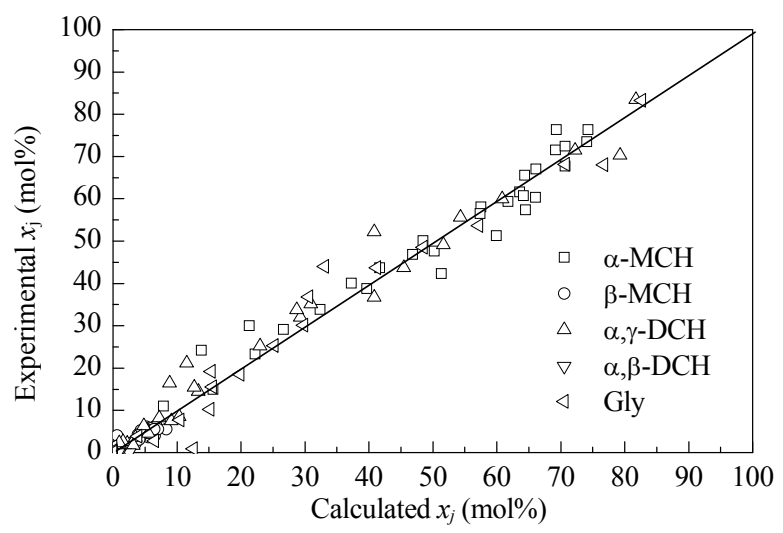

Fig. 5. Parity plot of the fitted data. 


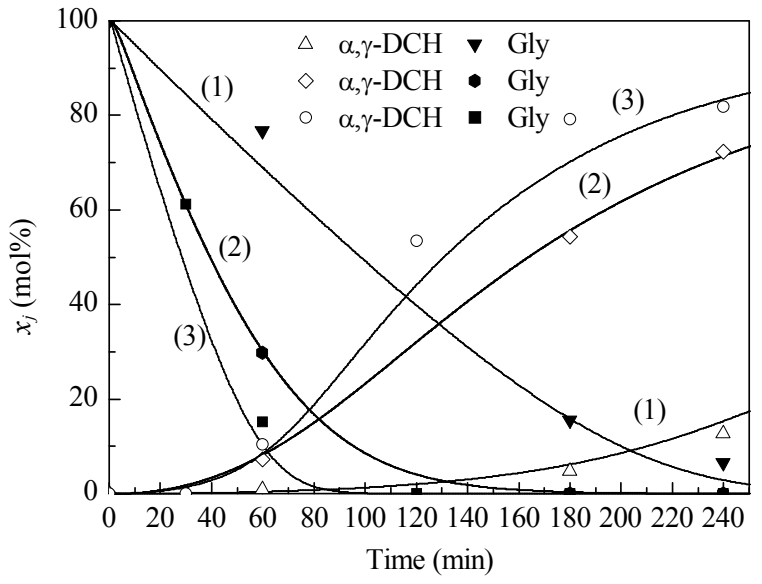

Fig. 6. $\alpha, \gamma$-DCH production and glycerol consumption for the runs at different pressure. (1) 1.0 bar; (2) 4.5 bar; (3) 8.0 bar.

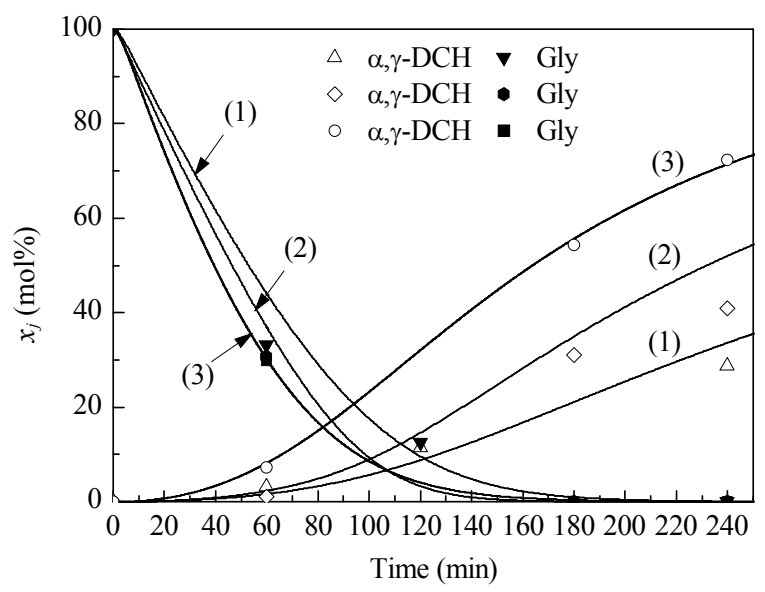

Fig. 7. $\alpha, \gamma$-DCH production and glycerol consumption for the runs at different catalyst amounts. (1) $2 \mathrm{~mol} \%$; (2) 4 mol\%; (3) 8 mol\%.

$\alpha, \gamma$-DCH with respect to $\alpha, \beta$-DCH. In Table 5 , two reactivity indexes referred to glutamic acid are also reported, expressed as the ratio between the kinetic constant of the generic catalyst and that of glutamic acid for the first and the second chlorination steps (reactions 1 and 3). From these ratios, it is evident that in the first chlorination reaction, the TGA catalyst was the most active while for the second chlorination, glutamic acid was the best.

Table 5

Ratios between the kinetic constants obtained by mathematical regression from the experimental runs performed using different catalysts.

\begin{tabular}{lrrcc}
\hline Run & $k_{1} / k_{2}$ & \multicolumn{1}{c}{$k_{3} / k_{4}$} & $k_{1 i} / k_{1 \mathrm{GLUA}}{ }^{*}$ & $k_{3 i} / k_{3 \mathrm{GLUA}}{ }^{*}$ \\
\hline 1 & 13.68 & 652.5 & 0.4496 & 0.2515 \\
2 & 18.17 & 8115.9 & 1.0000 & 1.0000 \\
3 & 9.94 & 270.1 & 0.0464 & 0.0394 \\
4 & 15.22 & 3475.6 & 0.7810 & 0.3393 \\
5 & 23.78 & 1949.3 & 0.5620 & 0.4003 \\
6 & 15.32 & $3.41 \mathrm{E}+8$ & 2.8301 & 0.8001 \\
\hline
\end{tabular}

* Reactivity index expressed as the ratio between kinetic constant of $i^{\text {th }}$ catalyst and that of glutamic acid.

\section{Conclusions}

Amino acid catalysts showed good activity and selectivity, which depended on the $\mathrm{p} K_{\mathrm{a}}$ value and molecular structure. ASPA and GLUA catalysts, which contain two carboxylic groups and have similar $\mathrm{p} K_{\mathrm{a}}$ values, show higher activity in glycerol conversion than CYS with a higher $\mathrm{p} K_{\mathrm{a}}$ and only one carboxylic group. However, the difference in carboxylic groups is not sufficient to explain the catalytic behaviour of GLUA and CYS, in particular, on comparing runs 3 and 8 (Table2, 3) that were conducted with the same carboxylic group concentration. In run 3 (CYS), the glycerol residue after $4 \mathrm{~h}$ reaction was $40 \%$ while complete conversion was obtained in run 8 (GLUA). By using amino acids as catalyst, it was demonstrated that catalyst $\mathrm{p} K_{\text {a }}$ played an important role on the selectivity, in agreement with ref. [10]. Although ASPA has a $\mathrm{p} K_{\mathrm{a}}$ slightly lower than GLUA, the selectivity to MCHs and DCHs was different: ASPA showed high selectivity to MCHs while GLUA has high selectivity to DCHs. The series of glycolic acids have higher catalytic activity compared to the amino acids, giving total conversion of glycerol under the same reaction conditions. For this series, different selectivity to MCHs and DCHs was observed. Their values do not depend on the $\mathrm{p} K_{\mathrm{a}}$ values of the corresponding catalysts, unlike the other series of catalysts. A reliable model was applied to describe the isothermal semi-batch runs and good agreement between experimental data and model prediction were obtained.

\section{List of symbols}

$F_{\mathrm{HCl}}{ }^{\mathrm{IN}} \quad$ molar $\mathrm{HCl}$ inlet flow-rate $(\mathrm{mol} / \mathrm{min})$

$F_{m} \quad$ rectangular pulse function for molar flow rate of the $m^{\text {th }}$ component (with accounting for sample withdrawing) ( $\mathrm{mol} / \mathrm{min})$

$[\mathrm{HCl}]^{*} \mathrm{HCl}$ interface concentration $\left(\mathrm{mol} / \mathrm{cm}^{3}\right)$

$J_{\mathrm{HCl}}$ mass transfer rate for $\mathrm{HCl}$ in the aqueous film $\left(\mathrm{mol} /\left(\mathrm{cm}^{3} \cdot \mathrm{min}\right)\right)$

[] concentration of the $\int^{\text {th }}$ component $\left(\mathrm{mol} / \mathrm{cm}^{3}\right)$

$K_{\mathrm{HC}}{ }^{j} \mathrm{HCl}$ solubility in the $j^{\text {th }}$ pure compound $\left(\mathrm{mol} / \mathrm{cm}^{3}\right)$

$n_{j} \quad$ moles of the $j^{\text {th }}$ component (mol)

$p \quad$ pressure (bar)

$r_{i} \quad$ kinetic rate constant $\left(\mathrm{mol} /\left(\mathrm{cm}^{3} \cdot \mathrm{min}\right)\right)$

$T$ reaction temperature $\left({ }^{\circ} \mathrm{C}\right)$

$V \quad$ volume of the reaction mixture $\left(\mathrm{cm}^{3}\right)$

$x_{j} \quad$ molar fraction of the $j^{\text {th }}$ component

\section{Greek letters}

$\beta \quad$ mass transfer coefficient $\left(\mathrm{min}^{-1}\right)$

$\gamma \quad$ solubility correction factor

\section{Acronyms}

AA acetic acid

ASPA aspartic acid

Cat generic catalyst

CYS cystein 


\section{Graphical Abstract}

Chin. J. Catal., 2014, 35: 663-669 doi: 10.1016/S1872-2067(14)60069-3

\section{Glycerol chlorination in a gas-liquid semibatch reactor: New catalysts for chlorohydrin production}

R. Vitiello, V. Russo, R. Turco, R. Tesser*, M. Di Serio, E. Santacesaria

University of Study of Naples "Federico II", Italy

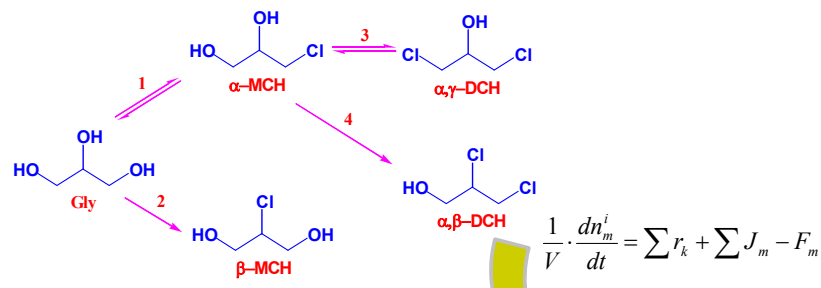

kinetic model and the kinetic and mass transfer parameters were obtained.

$\begin{array}{ll}\text { DGA } & \text { diglycolic acid } \\ \text { GA } & \text { glycolic acid } \\ \text { GLUA } & \text { glutamic acid } \\ \text { Gly } & \text { glycerol } \\ \text { MCH } & \text { smonochlorohydrins }(\alpha-\mathrm{MCH}+\beta-\mathrm{MCH}) \\ \text { TGA } & \text { thioglycolic acid. }\end{array}$

\section{Greek letters acronyms}

$\alpha$-MCH 1-chloro-2,3-propanediol

$\alpha, \beta$-DCH 1,2-chloro-3-propanol

$\alpha, \gamma$-DCH 1,3-chloro-2-propanol

$\beta$-MCH 2-chloro-1,3-propanediol

\section{References}

[1] Dasari M A, Kiatsimkul P P, Sutterlin W R, Suppes G J. Appl Catal A, 2005, 281: 225

[2] Alhanash A, Kozhevnikova E F, Kozhevnikov I V. Catal Lett, 2008, 120: 307

[3] Chiu C W, Dasari M A, Sutterlin W R, Suppes G J. Ind Eng Chem Res, 2006, 45: 791

[4] Johnson D T, Taconi K A. Environ Progr, 2007, 26: 338

[5] Zhou C H, Zhao H, Tong D S, Wu L M, Yu W H. Catal Rev, Sci Eng, 2013, 55: 369

[6] Cortright R D, Davda R R, Dumesic J A. Nature, 2002, 418: 964

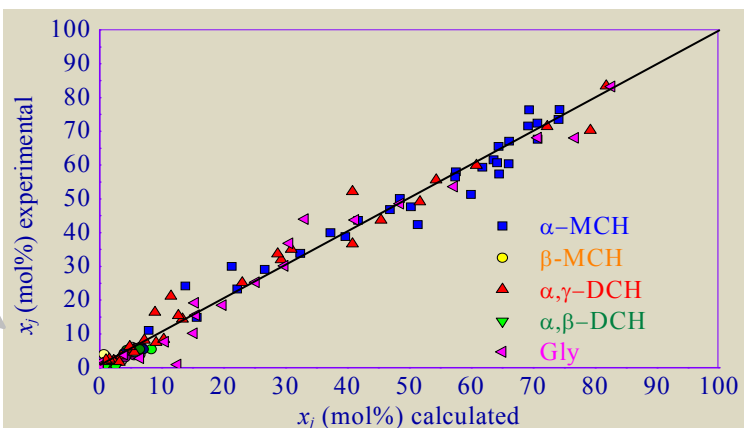

$x_{j}(\mathrm{~mol} \%)$ calculated 